\title{
Sustainability Impact on Construction Management in Developing Countries: Iraq as a Case Study
}

\author{
Basil Kasim Mohamed \\ School of Civil and Construction Engineering, Oregon State University, USA
}

\begin{abstract}
Sustainable development contributes to the economic and social advancement of construction projects. Ignoring sustainability during the cost estimating process associated with evaluation phase develops many problems of conventional decision methodology used in construction industry in the most of developing countries. This research focuses on sustainability which is the key factor in all decision making in design and construction processes. Therefore, Iraqi construction industry should respond to sustainability as a leading indicator of its infrastructure rebuilding. The construction management and sustainability could help to manage the rebuilding of the destroyed public infrastructure during the disaster wars periods passed thru thirty years ago and also to modernize of private buildings and plants. Field study has been carried out by adopting personal interviews and questionnaires conducted with experts, experienced consultants and designers working in many design organizations. The data collected has been analyzed and the results obtained show a clear weakness in the field of sustainability understanding, practicing and implementation. Moreover, the design work in Iraq is suffering from a lack of scientific techniques and a lack in experience in the domain of sustainability field. This will take an integrated approach to study the impact of sustainability on construction management which encompasses both public and private sector perspectives for building and engineering construction, and the roles played by all the participants in the construction team (owners, contractors, design professionals, and other supporting professionals).
\end{abstract}

Key words: Sustainability concepts, construction, management, engineering, developing countries, Iraq.

\section{Introduction}

Sustainability is defined by the ISO 15392 international standard as the state in which components of the ecosystem and their functions are maintained for the present and future generations (ISO Standard 2008). Buildings and structures enabled mankind to meet their social needs for shelter, to meet economic needs for investment and to satisfy corporate objectives. However, the satisfaction of these needs usually comes with a high price, i.e., an irreversible damage to our environment. This lead to a growing realization around the world to alter or improve the conventional way of development into a more responsible approach which can satisfy the needs for development without harming the world we live in.

Corresponding author: Basil Kasim Mohamed, $\mathrm{PhD}$, professor, research fields: project management, quality management systems, sustainability practices, engineering education. E-mail: basilkasim555@yahoo.com.
The ideas and strategies initiated by these world events have prompted positive actions and plans by many countries to implement this approach in their industries. Delivering sustainable construction requires action from all engaged in constructing and maintaining the structure or building including those providing design, consulting and construction services [1]. It requires willingness to explore new fields in construction approach and prepare to adopt new ideas and practices [2]. As global interest on sustainability has steadily blooming, developing countries should not fell short in its attitude on sustainability and sustainable construction.

The concept of sustainability in building construction has evolved over many years. The housing is now universally recognized as a human right and that effort to implement this right must be strengthened and accelerated in the developing countries. Sustainability in construction is not clearly recognized in most of developing countries included Iraq. The success and 
progress of human society depends on physical infrastructure, and a nation's economic strength is reflected in its infrastructure assets [3]. The traditional design process and construction in these countries focuses only on cost, quality and time, while environmental objective could add to these criteria minimization of resource depletion, reducing harmful emissions and maintaining a healthy environment together with conserving natural areas and biodiversity. That can be shown in Fig. 1 as a new paradigm to construction. In addition, economic, social and cultural dimensions of sustainability become very present especially in the global context [4].

\section{Sustainability in Construction}

The concept of sustainability in construction has initially focused on issues of limited resources especially energy, and on how to reduce impacts on the natural environment with emphasis on technical issues such as materials, building components, construction technologies and energy related design methods. The appreciation of the significance of non-technical issues has grown, giving recognition to economic and social sustainability concerns as well as cultural heritage of the built environment as equally important $[5,6]$.

Sustainable construction could be defined as a construction process which incorporates the basic themes of sustainable development. Such construction processes would thus bring environmental responsibility, social awareness, and economic profitability objectives to the fore in the pre project evaluation of built environment assets [7]. The green building movement is gaining momentum around the world. One of the biggest challenges facing contractors, designers and planners is how to ensure that our cities are developed and regenerated to be sustainable for the future. Building and construction companies in both public and private sectors should encourage the adoption of sustainable and environmental policies and practices yet there is evidence that in general it is a concept that is still misunderstood and unsupported by many project owners [8].

Sustainable construction is a process whereby, over time, sustainability is achieved. Sustainability should be applied into construction industry to influence the manner in which a project could be conducted to strike a balance between conserving the environment and maintaining prosperity in development. Attaining sustainability does not mean the eradication of adverse impact, which is an impossible vision at present, but rather the reduction of it to a certain reasonable level [2].

The direction of the construction industry is now shifting from developing with environmental concern as a small part of the process into having the development process being integrated within the wider

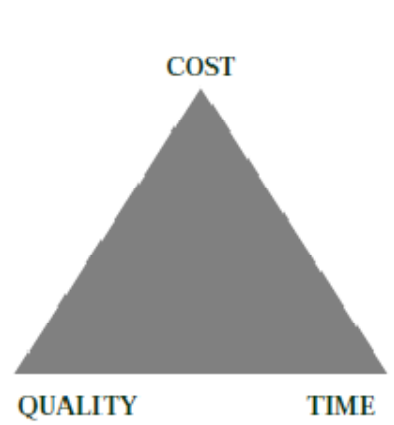

competitiveness factors in traditional building process

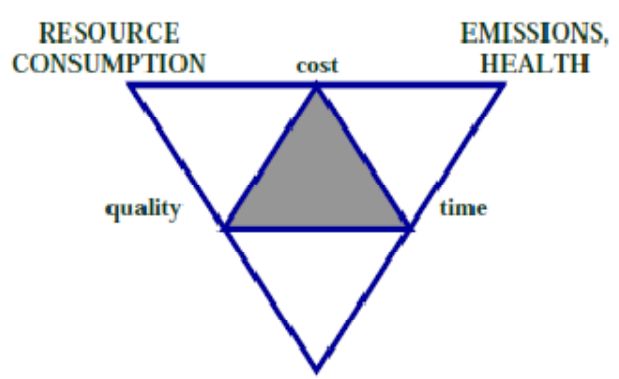

BIODIVERSITY
QUALITY OF LIFE,

QUALITY OF THE BUILT ENVIRONMENT

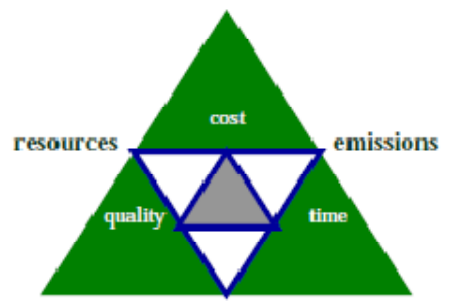

ECONOMICALLY biodiversity SOCIAL EQUITY SUSTAINABLE DEVELOPMENT CULTURAL HERITAC

Fig. 1 Sustainability new approaches [4]

CHALLENGES FOR 2000 AND BEYOND: sustainable processes and products 
context of environmental agenda. Thus, the activities of construction industry should work and comply with the needs to protect and sustain the environment.

Previously, the concern on environment is relatively a small part of most of construction development. However, with the growing awareness on environmental protection due to the depletion of nonrenewable resources, global warming and extremity of destruction to ecology and biodiversity impact, this issue have gain wider attention by the construction practitioners worldwide. The direction of the construction industry is now shifting from developing with environmental concern as a small part of the process into having the development process being integrated within the wider context of environmental agenda. Thus, the activities of construction industry must comply with the needs to protect and sustain the environment [9].
Presently, the concept of sustainable construction governs three main pillars: environmental protection, social well-being and economic prosperity. Fig. 2 shows the tree diagram of these three headings and their areas of concern [10] where it covers the main sustainability aspects as indicated in the international standard ISO 15392, and ISO 16813. Environmental protection concerns on the built environment and the natural environment. The built environment refers to the activities within the construction project itself, which may, if not handled effectively, have a serious adverse impact on the environment. Environmental sustainability is also concerned with the extraction of natural resources. Although builders have little influence over the extraction of natural resources, they can help discourage this activity by demanding less

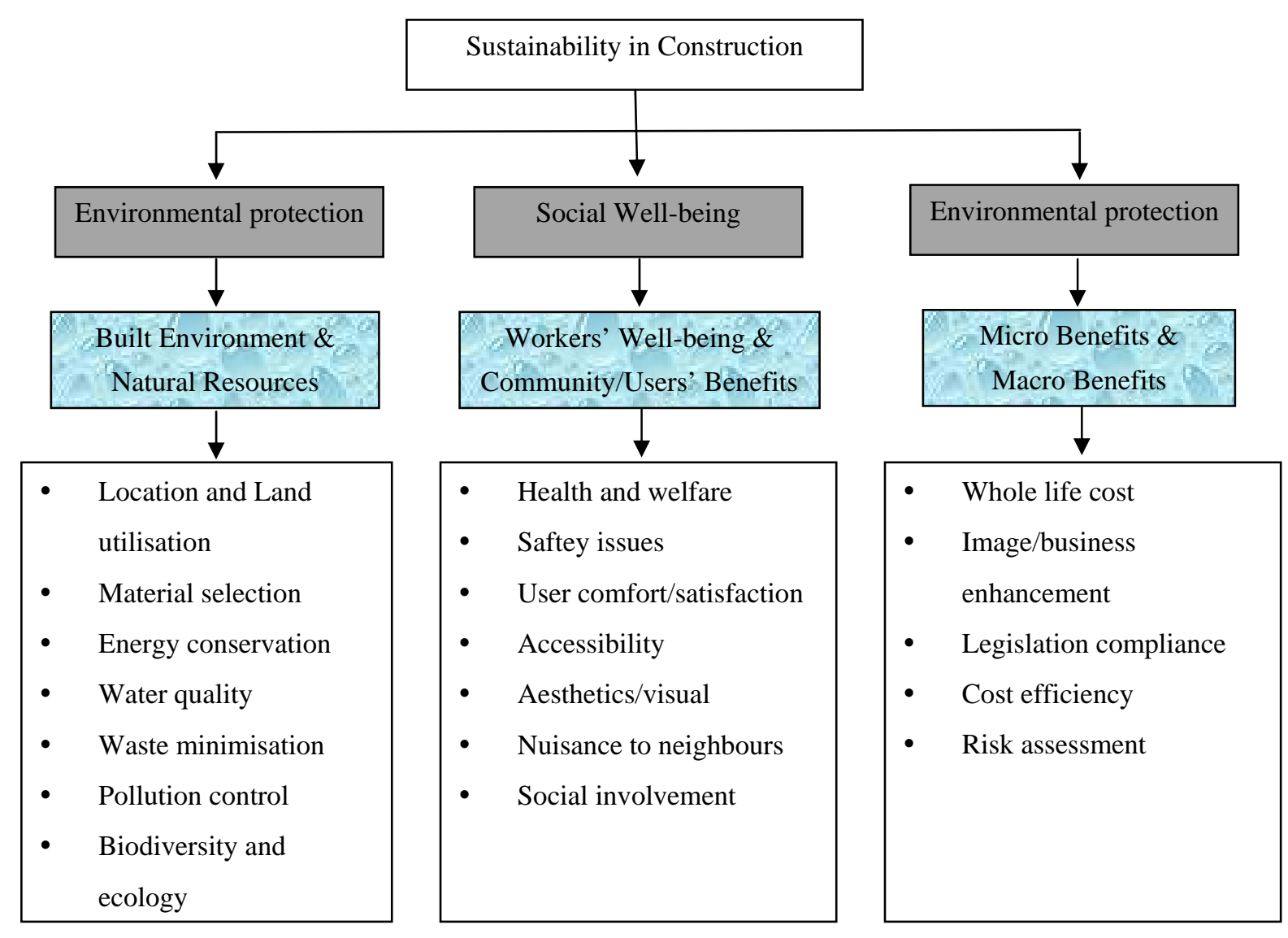

Fig. 2 The diagram of sustainability in construction [10]. 
non-renewable natural resources, more recycled materials, and efficient use of energy and mineral resources [11]. Social well-being concerns with the benefits of the workers and the future users. Basically, this aspect is concerned with human feelings: security, satisfaction, safety and comfort and human contributions: skills, health, knowledge and motivation [12].

\section{Infrastructure Reconstruction Problems in Iraq}

After the war 2003 in Iraq the infrastructure has been largely destroyed (about 70\%) roads, bridges, oil refineries, gasoline storage tanks, electric power plants, health and educational institutes, industrial facilities, public and residential buildings, communication system, even village water tanks. After the war's end, only $20 \%$ of Iraq's pre-war electrical generating capacity had been restored and daily blackouts were a fact of life. With the destruction of Iraq's power generating capacity, Iraq was no longer able to run its water-pumping stations and sewage treatment plants, depriving the Iraqi people of a hygienic source of water. In preparation for the October 2003 Madrid Donor Conference, the joint United Nations/World Bank team conducted an assessment of funding needs for reconstruction in Iraq during the period 2004-2007. The resulting report identified 14 sectors and associated funding needs of US\$36 billion. The Coalition Provisional Authority estimated an additional US\$20 billion in need including US\$5 billion for security and police and US\$8 billion for oil industry infrastructure [13].

Furthermore, a comprehension housing problems occurred and in its totality has resulted in a large proliferation of slums and unauthorized public building in all Iraqi cities and specially the capital Baghdad. Also, there were and till now many of unemployed educated, the destitute, senior citizens and working women, which when combined, comprise almost $1 / 4$ of Baghdad's urban population [14]. However, the government hadn't spent the large budget gained from potential resources on projects for the benefit of these groups. The demands are growing at a faster rate than the delivery system. Such disorientation puts severe environmental constraints upon cities dwellers. The government's efforts to solve this problem were not adequate by increasing investments in urban areas, leading to inadvertent migration resulting in these high densities, unliveable cities. This problem seems till now without apparent feasible solution in sight, rolling along like the veritable snowball, ever increasing in size [15].

In developing countries it is often not necessary to implement completely new building methods and materials in order to provide a safe life at a suitable human level. Local building practices in Iraq have not been assessed yet and weaknesses and strengths identified considering the local type and recurrence of natural hazards. Simple and expensive buildings were constructed during the past few years combined with poor quality construction methods. The materials used in these constructions were produced in the same traditional poor technologies without required care that must be taken to ensure that an adequate skills base exists for their use, or that training is provided, in order to avoid increased poor construction. The design of critical facilities and infrastructure that are essential for relief and recovery purposes in the event of a disaster are not given special consideration. The adoption of hazard-proof criteria set out in codes of practice for normal structures are not adequate in these buildings and the non-operation of these facilities was not socially acceptable. New developments should be implemented in construction performance based design of critical facilities to allow for the lower level of socially acceptable risk [16].

\section{Justifications and Objectives}

Developing countries wish to see all construction companies integrate sustainability into their development approaches to create more sustainable 
building projects. This will have important implications for construction companies involved in social rebuilding and will require placing sustainability instead of the traditional construction practice. Iraq looks to achieve economic development to secure suitable standards of living for people. It is well known that the consideration of sustainability early in a project's evaluation processes can result in less of an increase in capital costs than those made at a later stage. Therefore, the involved construction companies should be aware of the importance of early stage of potential project design decisions.

The developing cities in Iraq like Baghdad is having a rapid annual growth in construction sector which contributes about 6 million people. The existing multi story buildings and many public buildings are destroyed during the war 2003 and the civil war 2006-2008. Therefore, the reconstruction campaign becomes essential to construct new buildings by the real estate contractors and international construction companies which can create a significant stress on water, energy and waste management.

This paper is an attempt to address the sustainable construction approach and how to be accepted in the developing countries based on existing socio-economic and environmental condition. Construction sector in Iraq has considered its projects to have long life cycle value especially during infrastructure rebuild. After the war Iraqi engineers realized that they should work on processes, services to the users of facilities. Quite recently infrastructure and housing are stated to be the main users of resources and the main producers of environmental burdens. The quality of the built environment is also claimed to contribute to the quality of life. Therefore, Iraqi construction sector should without delay develop its construction processes towards sustainable direction to remedy the built environment.

The main research objectives are:

- Describing a comprehensive sustainability concept understanding, practicing, and implementing.
- Identifying current approaches to building construction practices.

- Identifying the sustainability ideas, evaluation and continuous improvement in Iraqi companies.

- Exploring the reality of sustainability impact on project construction in Iraq as a developing country.

\section{Field Survey and Methodology}

The field survey was conducted by participation of many Iraqi construction companies. These companies have business contracts and actual involvement in rebuilding projects in Iraq. A questionnaire was used to cover the qualitative implementation of sustainability principles, various concepts, evaluation and continuous improvement of Iraqi infrastructure. The main focus was to identify the sustainability impact on the construction management in the Iraqi companies.

The questionnaire was prepared according to the main sustainability principles indicated in the literature review. The survey has been carried out in Iraq to study the reality of construction management relative to sustainability impact and to find how the Iraqi engineers respond to sustainability concepts and principles, and was conducted for a statistical sample of 20 (public and private) construction companies in Iraq.

The research sample included 50 personnel who have significant role in construction field such as project managers, company managers, contractors, professional engineers, social, and economical professionals. These participants have an active experience in construction field between 10 to 30 years. The majority of them have been involved with more than 20 projects with project cost within the range of 1 to more than 10 million dollars. The respondent profiles for the field survey for the construction companies are $70 \%$ public sector and $30 \%$ private sector. The questionnaire lists distributed were 70 and the collected was 20 not complete thus ignored and the 50 complete respondents profile is demonstrated in Table 1. 
Table 1 The participants profile.

\begin{tabular}{|c|l|c|c|}
\hline No. & \multicolumn{1}{|c|}{ Participants } & Numbers & Percentages \\
\hline 1 & Companies Managers & 5 & $10 \%$ \\
\hline 2 & Project Managers & 6 & $12 \%$ \\
\hline 3 & General Contractors & 6 & $12 \%$ \\
\hline 4 & Social Professionals & 4 & $8 \%$ \\
\hline 5 & Economy Professionals & 4 & $8 \%$ \\
\hline 6 & Architects & 7 & $14 \%$ \\
\hline 7 & Civil Engineers & 7 & $14 \%$ \\
\hline 8 & Mechanical Engineers & 4 & $8 \%$ \\
\hline 9 & Electrical Engineers & 3 & $6 \%$ \\
\hline 10 & Environment Engineers & 4 & $8 \%$ \\
\hline \multicolumn{2}{|c|}{ Totals } & 50 & $100 \%$ \\
\hline
\end{tabular}

\section{Results and Discussion}

The literature review shows that the sustainability concept is not well defined, recognized, and implemented in the construction industry in developing countries. To show how far sustainability concept has penetrated the construction industry, a field survey has been conducted among construction companies in Iraq which focuses on the research sample identifying this subject and whether they have incorporate knowledge within their current projects.

The data and information collected from participating companies were analyzed to recognize the reality of sustainability concept understanding, practices, future perspective for implementation, and the impact of sustainability on various aspects in Iraqi rebuilding projects.

The data gathered was analyzed qualitatively and quantitatively. The statistical analysis was used to calculate straightforward totals, percentages and averages. Qualitative technique was applied to make sense of meanings. Interviews were used to connect statements, opinion and comments to provide a complete picture. The results are discussed as follows:

\section{Sustainability Understanding and Implementation}

The level of knowledge among research sample is demonstrated in Fig. 3 with regards to sustainability concept, the respondents were asked to rate their knowledge on this subject matter and what they perceived, based on their experience. As shown in Fig. 3 only $18 \%$ of the respondents have a moderate sustainability understanding relies on written materials or very limited internet websites to improve their knowledge about sustainable construction. Other sources of knowledge are through education, seminars and conferences. Meanwhile the majority of respondents have $42 \%$ of very poor knowledge about sustainability. The learning level indicates that most of the companies should promote sustainability concept within their organizations.

Aligned with the level of knowledge revealed by the respondents, the level of implementation is also at very poor level 50\% and 35\% considered it low as shown in Fig. 4, and none of the respondents considered that the implementation of sustainable practices is excellent.

The respondents were requested to give their opinion on the prospect of sustainable construction application in Iraq in the next 5 years depending on current construction projects applications. Fig. 5 shows clearly that $45 \%$ of the respondents believed that in the next five years, there will not be much change and the level is still at low level. About 15\% of respondents believed that it will get a moderate level, while $10 \%$ of the respondents considered it would be good, while the whole respondents believe that no way to get excellent level.

\section{Traditional Construction Design Approach}

The sustainable construction concepts are not clearly recognized in Iraqi construction field as shown in Fig. 3. The traditional design approach is still the main practice in the construction companies in Iraq which focuses on cost, quality and time. Fig. 6 shows the importance of each factor. The majority of the survey respondents $60 \%$ considered that cost is the major factor to be considered during design stage of construction projects. Regarding to time factor there 
was only $25 \%$ of the respondents who indicate that project scheduling and maintaining the total project duration is very important in project construction planning. The respondents didn't focus on quality as an important factor to achieve the projects successfully where only $15 \%$ of them consider it important to conform to standards and specifications stated in the project design.

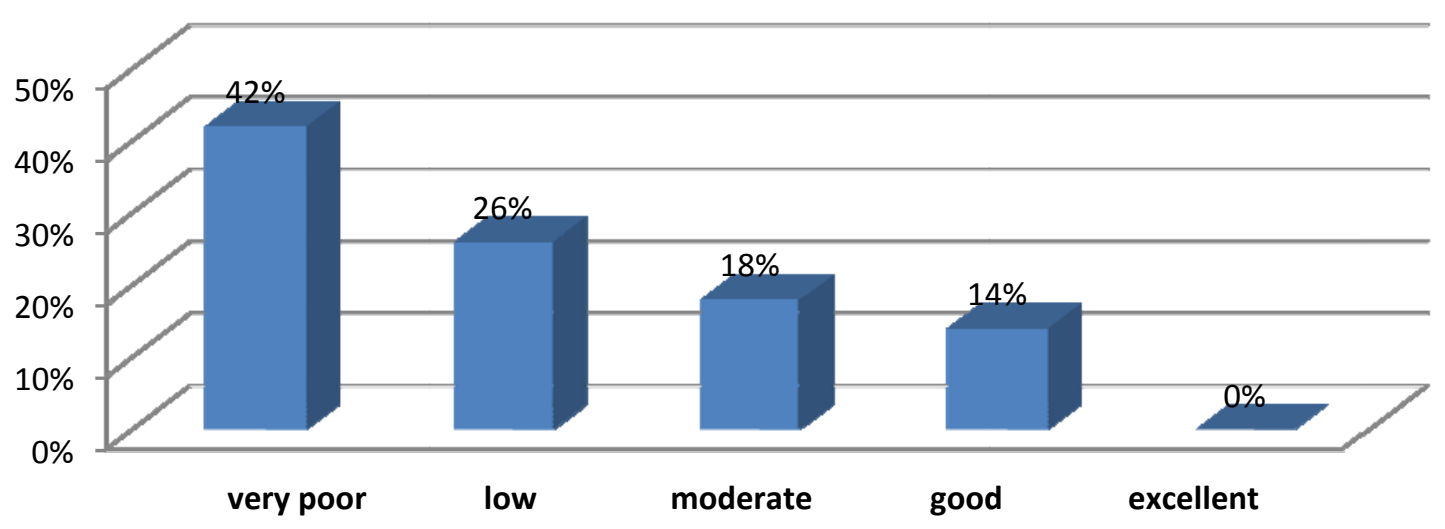

Fig. 3 Levels of understanding sustainability concept.

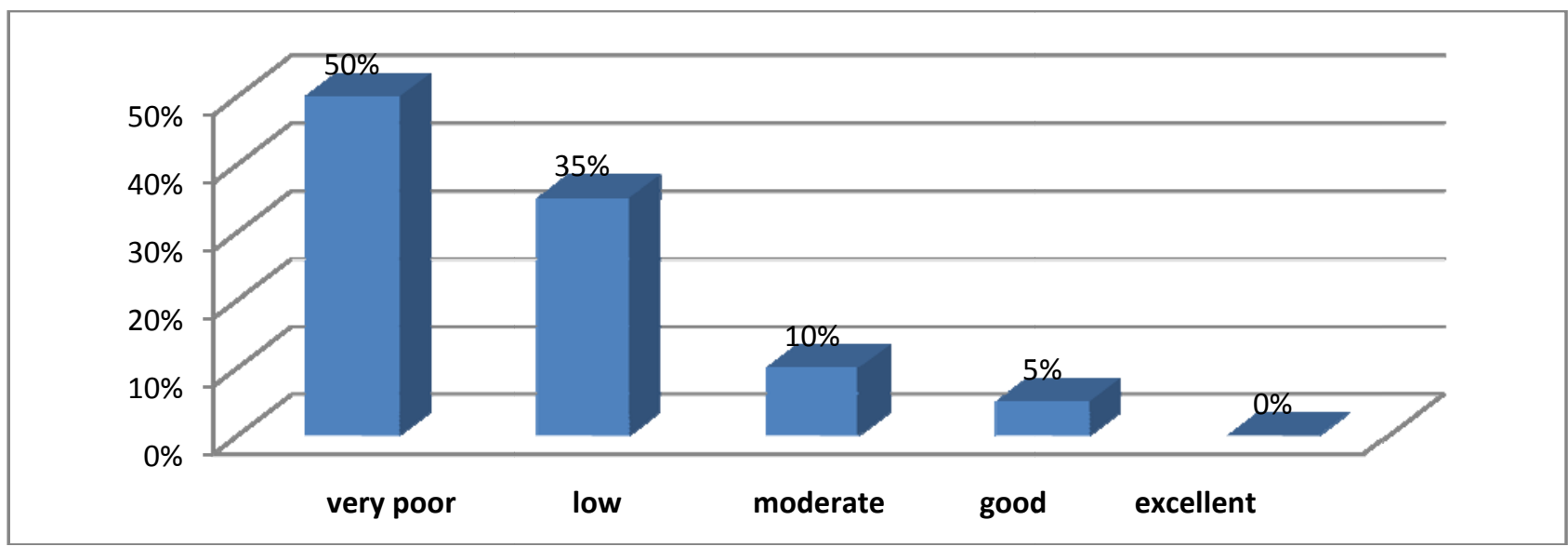

Fig. 4 Implementation Levels of Sustainability Practices in Iraq.

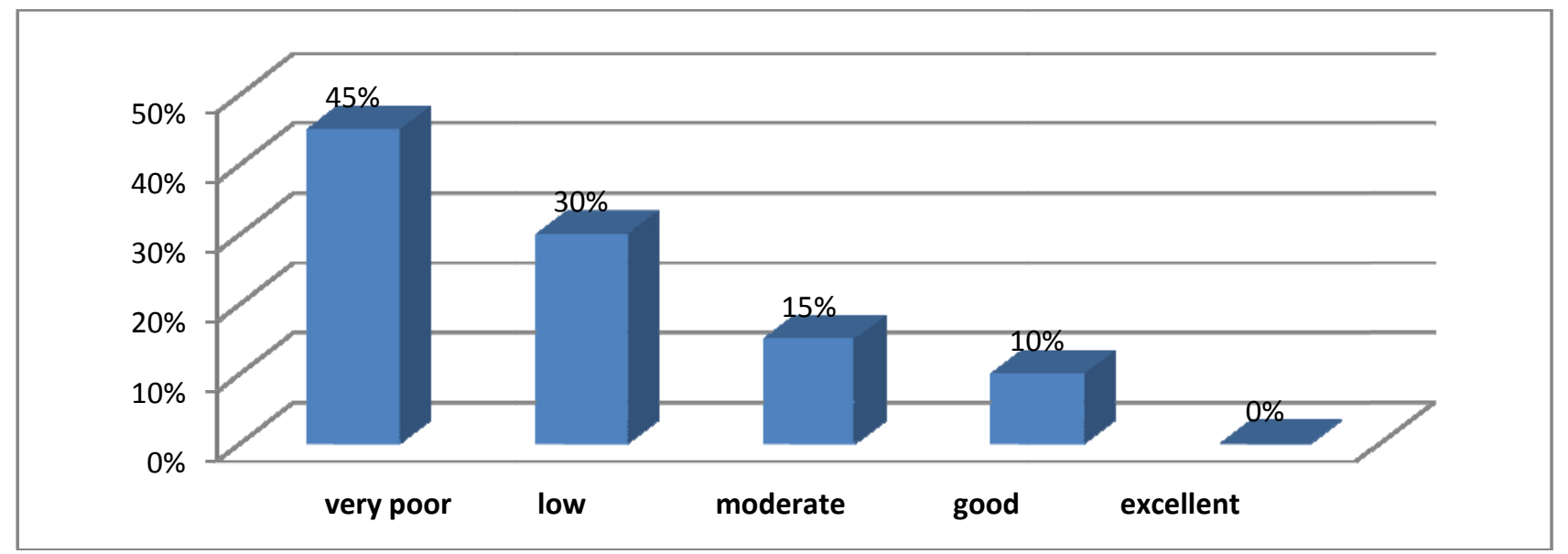

Fig. 5 Prospect of Sustainability Practices in 5 Years in Iraq. 

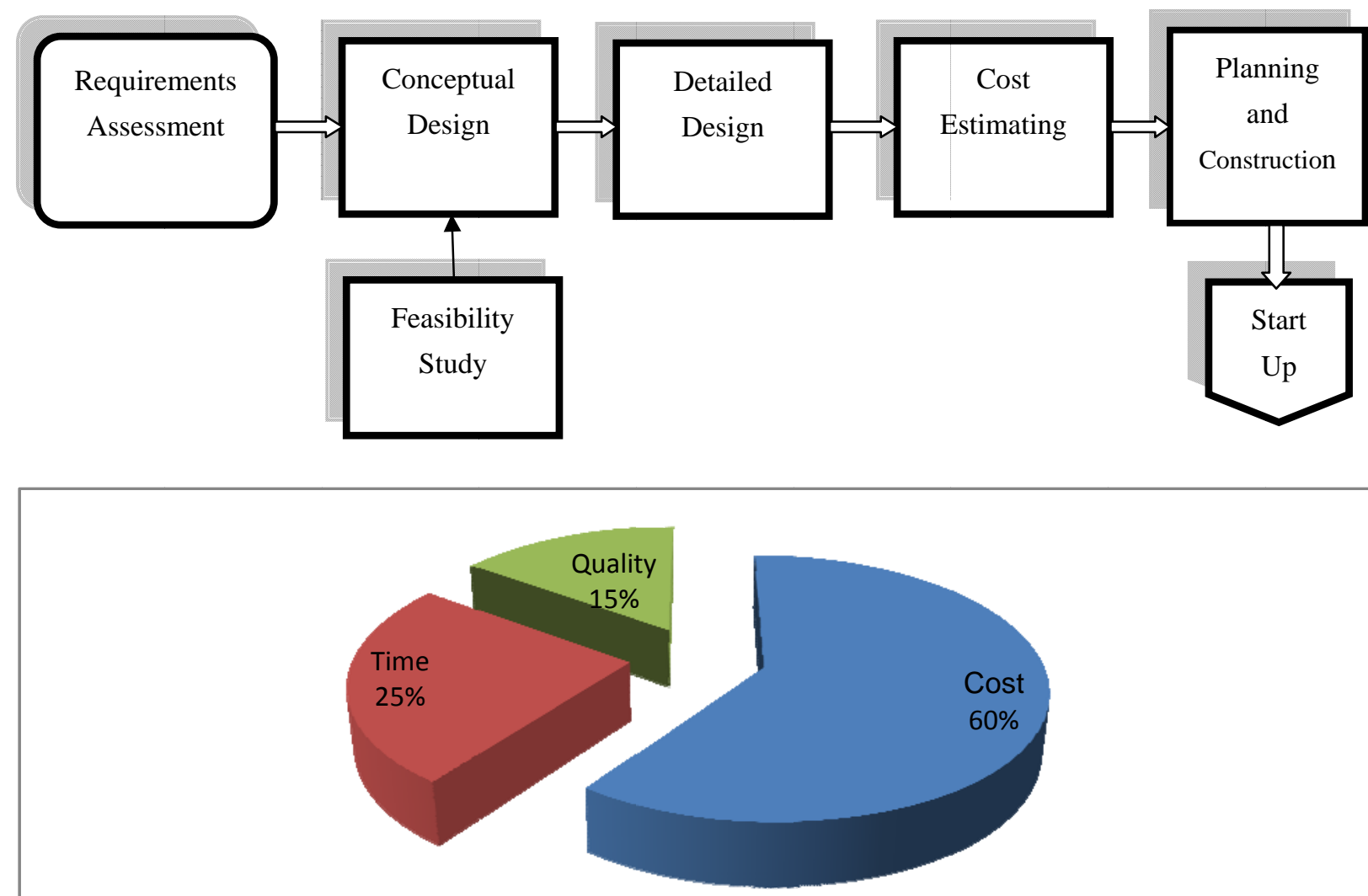

Fig. 6 Traditional design approach.

\section{Sustainable Construction Design Approach}

The research sample was asked simultaneously about the impact of the sustainability approach on the construction management practices to verify their responds towards this new issue. As shown clearly in Fig. 7, the majority of the respondents 55\% consider that the most important factor is the economy, while 35\% of them considered the environment requirements in new sustainable construction design are important, and only $10 \%$ of the respondents takes the social factor of the sustainable design approach into consideration which indicates clearly how the disaster conditions passed in Iraq reflect a great ignorance for human life related to providing suitable residential homes, These results show that the traditional construction approach is still applicable in the Iraqi construction companies while the sustainability impact has not essential basis to be practiced or implemented in construction design. These companies could not realize that the sustainable design is an integrated design where each component is considered as a critical part of the whole successful sustainable design compared with traditional design. Early decisions have the greatest impact on energy efficiency, passive solar design, day lighting, and natural cooling. Furthermore, the sustainable buildings do not have to cost more, nor are they more complicated than traditional construction.

Fig. 8 shows a comparison between the traditional and sustainability concepts simultaneously where the blue line refers to the dominant traditional design approach which is upper than the sustainability importance red line. Fig. 9 shows the sustainability design approach where sustainability requirements could be implemented during the early stage of the design process and evaluated at each design phase throughout the value engineering. 


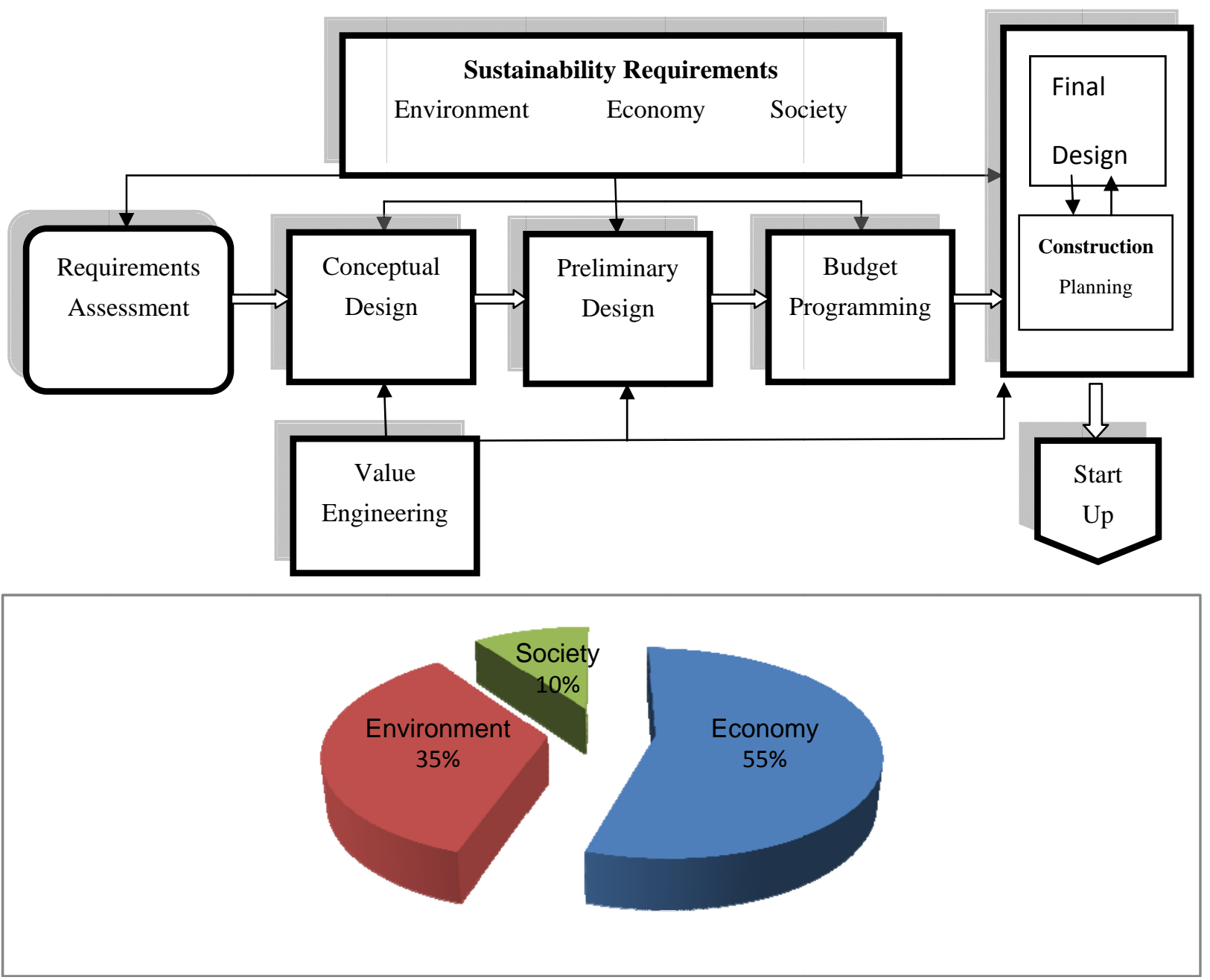

Fig. 7 Sustainable design approach.

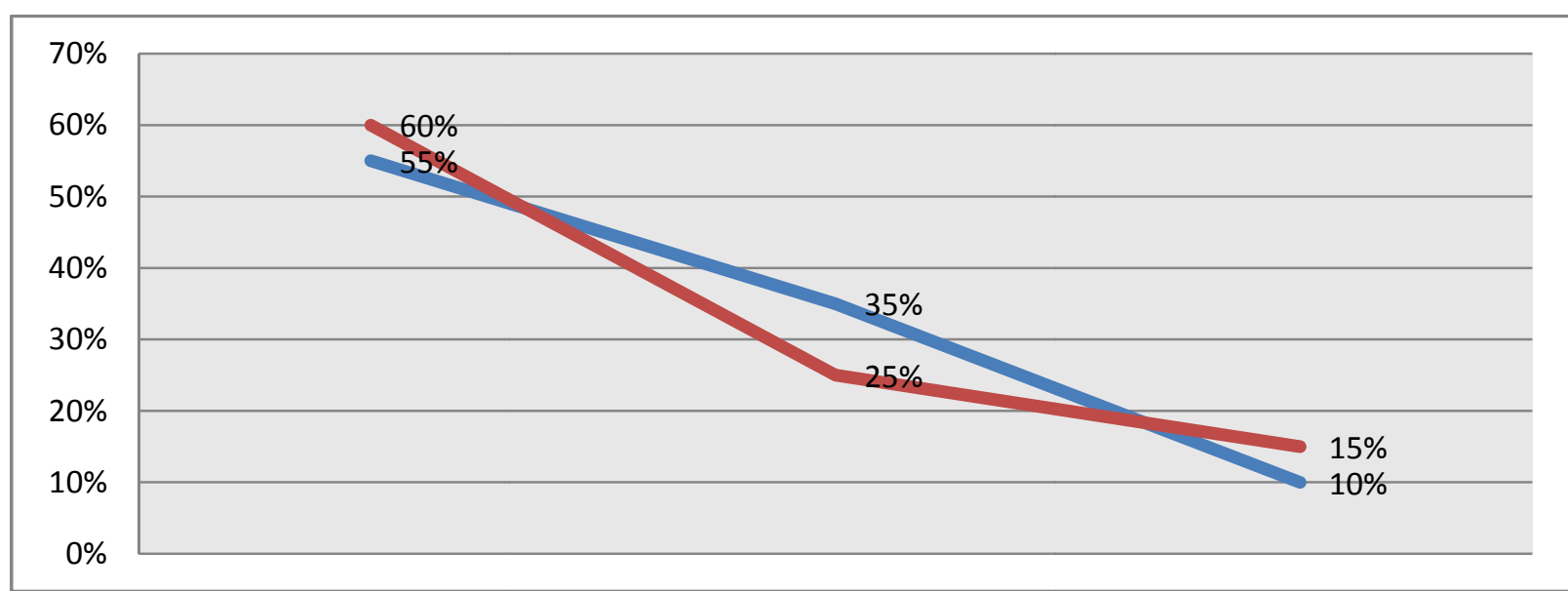

Fig. 8 Comparison between the traditional and sustainability concepts importance.

\section{Sustainability Principles}

The concept of sustainable construction that governs environmental protection, social well-being and economic prosperity has been investigated to illustrate how the construction companies in Iraq respond to these areas of concern and to show the sustainability impact on current construction player, where the 
respondents indicate clearly that these companies could be acting successfully to implement sustainable construction by creating suitable built environments, and restoring damaged and polluted environments.

They realize that in order to achieve sustainability, the construction management policy in Iraq should change the processes of creating the built environments. This could be achieved by changing the linear processes to cyclic processes within the construction industry, and it is shown in Fig. 9 where the respondents revealed that the of various environment aspects have a significant importance as following: (location and land utilization 15\%,material selection 20\% energy conservation $16 \%$, water quality $18 \%$, waste minimization $8 \%$, pollution control $13 \%$, and biodiversity and ecology $10 \%$ ) for changing the way in which all the construction activities are undertaken.
Regarding to the social factors mentioned in Fig. 2, the respondents show the construction companies that involved in real projects to rebuild the infrastructure in Iraq should take into consideration the important sustainability implications of social requirements which are shown in Fig. 10, where the research sample realized the importance of health and welfare by $20 \%$, safety $16 \%$, user comfort and satisfaction $18 \%$, accessibility $14 \%$, aesthetics $12 \%$, nuisance to neighbors $8 \%$, and social involvement $12 \%$.

As shown previously in Fig. 6 that the majority of the respondents considered that cost and the economy are the major important factors whether in traditional or in sustainable building construction approaches. The results shown in Fig. 11 indicated that the respondents found the importance of the economical aspects as

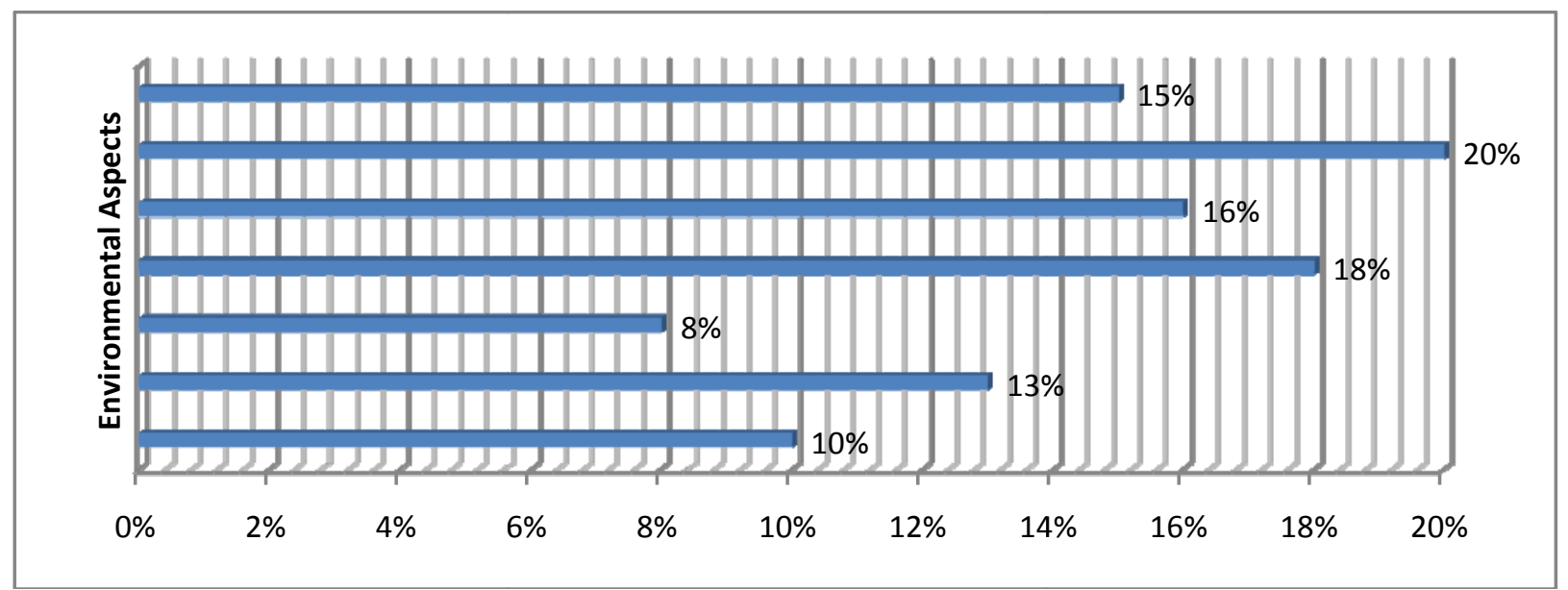

Fig. 9 The importance of the environmental aspects.

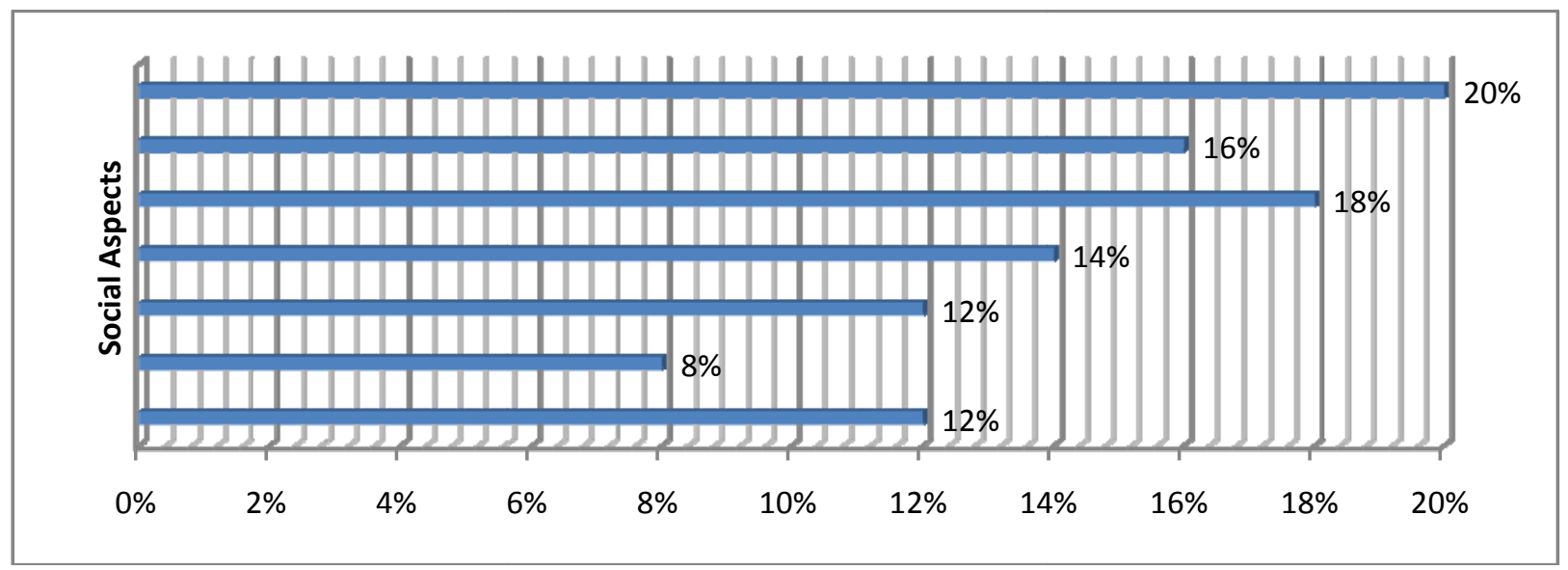

Fig. 10 The importance of the social aspects. 


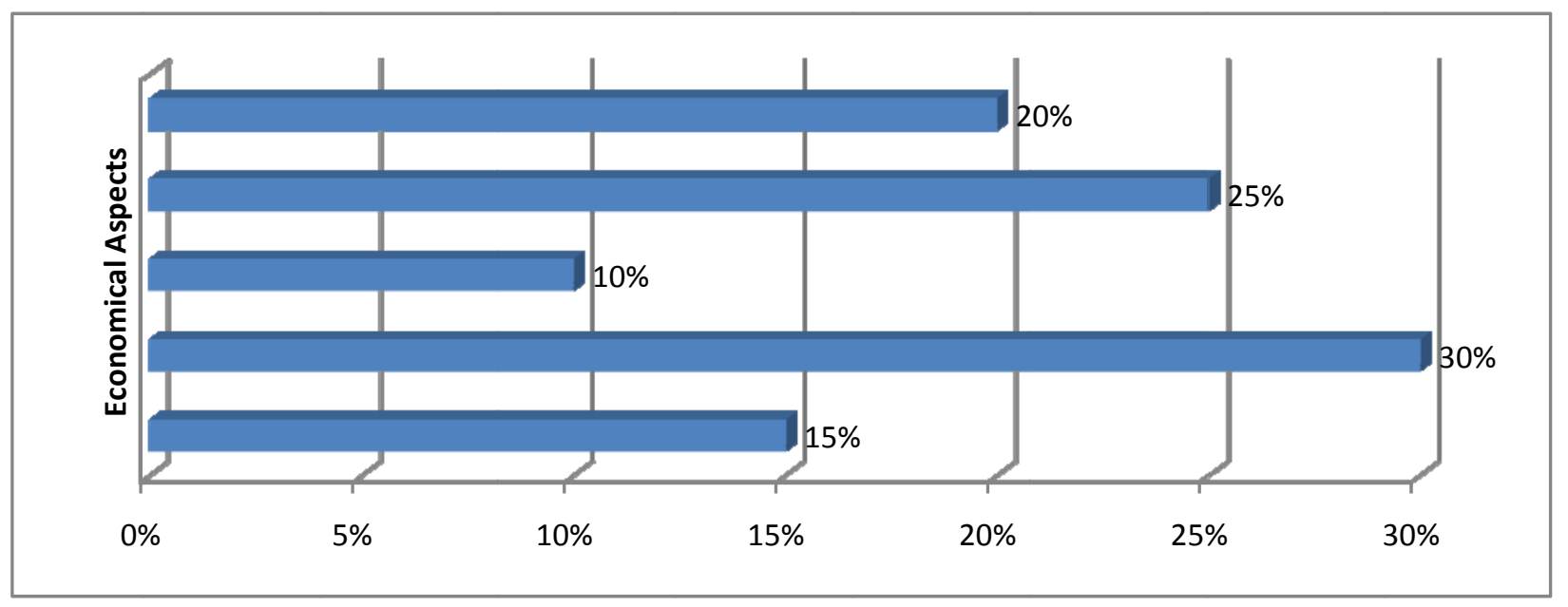

Fig. 12 The importance of the economical aspects.

following (whole life cost 20\%, image and business enhancement $25 \%$, legislation compliance $10 \%$, cost efficiency $30 \%$, and risk assessment $15 \%$ ).

\section{Conclusions}

The main conclusions deduced from the research can be illustrated as followings:

(1) There are many respondents stress the need for enforcement through law and legislation to increase educational opportunities to have more knowledge about sustainability concepts and implementation in construction field.

(2) The respondents highlighted the necessity of professionally qualified players in the construction industry in Iraq to improve the sustainability practices and implementation properly.

(3) The results showed that the respondents have poor knowledge about sustainability, where the learning level of sustainability concepts in the construction companies should be promoted within their organizations. This requires cooperation with construction experts for the development of appropriate educational and training.

(4) The Iraqi construction companies could not realize that the integrity of the successful sustainable design compared with traditional design, and the sustainable buildings which do not have to cost more, nor are they more complicated than traditional construction.

(5) Iraq is facing a disaster conditions and serious need to accelerate sustainability implementation in reconstruction of the infrastructure in general and to raise the living standards of the populations, meanwhile, reducing energy costs, pollution and to promote the use of renewable materials and energies that should be the priority in any action taken to protect the environment.

(6) Many respondents believed that sustainability can be implemented successfully in the Iraqi construction projects if the management policies oriented by governmental financial support, where they still suppose that sustainable practices increase project cost.

(7) The respondents show a high consideration to the importance of various sustainability principles which can improve the whole infrastructure reconstruction projects in Iraq.

(8) There is a need for a better understanding of the management performance after disaster conditions where the infrastructure and traditional building materials and technologies have to be promoted research into design of structures to reduce the effects of expected hazards.

(9) Post-disaster reconstruction projects present a real necessity for hazard-proof measures in 
construction and land use planning which sustainability approach provided. Delegation of national, international companies and humanitarian agencies should coordinate in such conditions.

\section{References}

[1] WS Atkins Consultants, Sustainable Construction: Company Indicator, CIRIA C563. London: CIRIA, 2001.

[2] Ofori, C. Briffett, G. Gang and M. Ranasinghe, Impact of ISO 14000 on construction enterprises in Singapore, Construction Management and Economics 18 (2000) 935-947.

[3] K. Chaharbaghi and R. Willis, Study and practice of sustainable development, Engineering Management Journal 9 (1) (1999) 41-48.

[4] P. Huovila, Managing the life cycle requirements of facilities, Proceedings of 8DBMC Symposium, Performance, Service Life Prediction and Sustainable Construction, Vol. 3, Vancouver, May 30-June 3, 1999, pp. 1874-1880.

[5] S. Parkin, Context and drivers for operationalizing sustainable development, Proceedings of ICE, vol. 138, Nov. 2000, pp. 9-15.

[6] S. Parkin, Sustainable Development: the concept and the practical challenge, Proceedings of the Institution of Civil Engineers: Civil Engineering, vol. 138 (special issue 2), 2000, pp. 3-8.

[7] N. Raynsford, Sustainable construction: The government's role, Proceedings of ICE, Vol. 138, Nov. 2000, pp. 16-22.
[8] D. G. Selmes, Towards sustainability: Direction for life cycle assessment, PhD thesis, Heriot Watt University: Edinburgh, UK, 2005.

[9] Hayles, The role of value management in the construction of sustainable communities, The Value Manager, vol. 10, No. 1, available Online at: http://www.hkivm.com.hk /publications/04/TVM2004-.

[10] N. Zainul Abidin, Using value management to improve the consideration of sustainability within construction, Ph.D. Thesis, Loughborough University, United Kingdom, 2005.

[11] B. Addis and R. Talbot, Sustainable Construction Procurement: A Guide to Delivering Environmentally Responsible Projects, CIRIA C571, London: CIRIA, 2001.

[12] P. L. Lombardi, Responsibilities towards the coming generations: Forming a new creed, Urban Design Studies 7 (2001) 89-102.

[13] United Nations/World Bank, Joint Iraq needs assessment, A report prepared by the Madrid Donor Conference in October, 2003 UN/World Bank Joint Iraq Needs Assessment October 2003.

[14] Homeless families and public buildings, A report published by the Ministry of Immigration, Baghdad, Iraq, 2004.

[15] Housing Problems in Iraq after the War 2003, A report published by Housing Humanitarian Society, NGO, Baghdad, 2005.

[16] Agenda 21 for Sustainable Construction in Developing Countries - A Discussion Document, CIB \& UNEP-IETC Publication, CSIR Building and construction Technology, South Africa, 2002. 